\title{
Epidemiological, Nutritional and Factors Associated with Infant Bronchiolitis in Hospitals: Case of the City of Lubumbashi (DR Congo)
}

\section{Boniface Fievey Makam¹, Gray A. Wakamb Kanteng ${ }^{1 *}$, Stanis Okitotsho Wembonyama ${ }^{1}$, Oscar Numbi Luboya ${ }^{1.2}$}

${ }^{1}$ Department of Pediatrics, University of Lubumbashi, Lubumbashi, DR Congo

${ }^{2}$ Public School Health, University of Lubumbashi, Lubumbashi, DR Congo

Email: *gkanteng@yahoo.fr

How to cite this paper: Fievey Makam, B., Wakamb Kanteng, G.A., Wembonyama, S.O. and Numbi Luboya, O. (2017) Epidemiological, Nutritional and Factors Associated with Infant Bronchiolitis in Hospitals: Case of the City of Lubumbashi (DR Congo). Open Access Library Journal, 4: e3710.

https://doi.org/10.4236/oalib.1103710

Received: June 5, 2017

Accepted: June 25, 2017

Published: June 28, 2017

Copyright $\odot 2017$ by authors and Open Access Library Inc.

This work is licensed under the Creative Commons Attribution International License (CC BY 4.0).

http://creativecommons.org/licenses/by/4.0/

c)

\begin{abstract}
Introduction: The objective of this study is to determine the incidence of acute bronchiolitis of infants in an urban area of the Democratic Republic of Congo to establish the epidemiological, clinical and nutritional profile of affected infants. Methodology: A cross-sectional descriptive study was conducted in Lubumbashi (DR Congo) at three hospitals over a 2-year period from 2013 to 2014. A total of 321 acute bronchiolitis was collected in infants Less than 24 months. Results: A hospital incidence of $3.8 \%$ was found. Bronchiolitis occurred most from December (8.7\%) until March (8.7\%), and the peak was observed in February, i.e. $24.9 \%$ of cases, which corresponds to the great rainy season. The average age of children with was calculated $7.78 \pm 6.43$ months. The prevalence of underweight was $40.6 \%(n=129)$. There was a significant association between pathology and prematurity $(\mathrm{p}=0.00, \mathrm{OR}=$ $111[20.2-614.5])$ with associated pathologies $(\mathrm{p}=0.02 \mathrm{OR}=8$ [0.9-64.5]). Conclusion: The incidence of bronchiolitis has declined in comparison to previous studies in the context of our study setting, but it may be regressed if targeted public health measures are taken.
\end{abstract}

\section{Subject Areas \\ Infectious Diseases, Pediatrics}

\section{Keywords}

Bronchiolitis, Infant, DR Congo 


\section{Introduction}

Bronchiolitis is an inflammation of the pulmonary bronchioles [1]. The diagnosis is clinical and is based on signs of low respiratory infection (cough, respiratory congestion, sibilant rales, crepitations), in an infant under 2 years of age, with or without respiratory discomfort (polypnea, expiratory blockage, dyspnea, Thoracic distension) [2]. It is the first of all diseases of the lower respiratory tract [2] [3] [4] [5]. The factors that favor the outbreak of the pathology are: age, season, child constitution, sex, nutrition, environment: promiscuity, smoking mother, pollution. In practice, risk factors are grouped into 5 major groups for some authors [6] [7]. Thus we have: the fragility of the child, life in collectivity, the smoking of the entourage, socio-economic conditions and urbanization.

Acute respiratory infections are the leading cause of mortality and morbidity in young children around the world. They account for about $25 \%$ of the causes of death in children under 5 years of age [5] [8] [9].

A study carried out in Tunisia during the first quarter of 1999 showed that out of a population of 1340 children admitted during the period, $10 \%$ were admitted for a respiratory problem related to bronchiolitis [9] [10] [11].

A report by the Ministry of Health published in 2011 places respiratory infections in second place of the causes of infant morbidity and third in the causes of infant mortality in the Democratic Republic of Congo [12] [13].

Numerous studies carried out in other heavens [9] [10] [14] have clearly demonstrated a relationship between the occurrence of bronchiolitis and certain risk factors. For example, a study carried out in Italy between 1999 and 2002 revealed the following observation [15]: the peak of the epidemic occurred in February, while the lowest prevalence was recorded in November [16] [17]. A high proportion of subjects had a low birth weight and most were born prematurely. For this study, gestational age, birth order, birth weight and exposure to tobacco smoke affected the prevalence and severity of the disease [13] [18] [19] [20].

Our study aims to contribute to the improvement of the management of acute bronchiolitis of the infant. Specifically, our study aims to: Determine the incidence of acute bronchiolitis in our environment, the epidemiological and clinical profile of children affected, and the nutritional status of the children concerned.

\section{Methodology}

\subsection{Framework of Study}

This work was carried out in the geographical area of the city of Lubumbashi, the second city of the DR Congo. Three hospitals have been used as a data collection site, depending on whether they organize a dedicated pediatric unit and have a high pediatric attendance rate, especially for infants under 24 months of age. Our choice has also been guided by the fact that these structures have a rationalization of care based on an expertise of doctors, specialists or accustomed to the infantile care. These are the following health facilities:

- Jason Sendwe General Referral Hospital, a University teaching hospital (tertiary level), with a mean of 1257 children admitted per year during our study 
period.

- Lubumbashi University Clinics, a University teaching hospital (tertiary level), with a mean of 602 children admitted per year during our study period.

- Watoto Health Center, a private specialized pediatric clinic, with a mean of 2368 children admitted per year during our study period.

\subsection{Type, Duration and Period of Study}

This is a cross-sectional descriptive study carried out in three hospitals in the city of Lubumbashi. The study covers the period from $1^{\text {st }}$ January 2013 to 31 December 2014, a two-year study period.

\subsection{Population and Sampling}

\section{- Target population}

Our target population is infants living in the city of Lubumbashi.

\section{- Sample type and size}

We conducted a sampling of convenience. A total of 321 cases of bronchiolitis were collected, as an exhaustive sample based on the inclusion and exclusion criteria described below.

\section{- Inclusion Criteria}

This study included infants who met the following criteria:

Being a resident of Lubumbashi city town;

Having a lower or equal age to 24 months;

$>$ Being hospitalized for bronchiolitis in one of the designed hospitals.

The diagnosis of bronchiolitis was made on the basis of the following criteria: At an age less than or equal to 24 months, developed a cold after which the clinical examination revealed the presence of sibilant rales on auscultation, with The presence of a radiograph of the thorax suggestive of bronchiolitis (horizontalization of the dimensions, widening of the intercostal spaces, trapping of air, flattening of diaphragmatic hemi-cups).

\section{- Exclusion Criteria}

Excluded from this study were:

All cases of dyspnea with sibilances can be explained e d by another cause that bronchiolitis (heart defects, ed foreign body intra-pulmonary, asthma infant, etc.)

Outpatient bronchiolitis

> All cases missing evident clinical elements for the diagnosis of bronchiolitis, even if it was the chosen diagnosis by the examiner.

Thus, out of 8454 records examined, 418 records were suspected of bronchiolitis, but only 321 were selected according to the previous criteria.

\subsection{Study Parameters}

The following parameters were collected and were the subject of our study: Age (in months), Sex, Weight (in Kg), period of consultation, Residence area, reason for consultation, duration of hospitalization, evolution. 


\subsection{Data Collection}

We used a documentary review based on hospital records and patient registers. The data were collected on the basis of a sheet prepared for this purpose and which enabled the recruitment of cases.

\subsection{Data Processing and Analysis}

The data were entered on a computer using the Epi-info 6.4 software, which generated descriptive aspects of the analysis, including frequency distributions. The $\mathrm{Chi}^{2}$ or Fisher test made it possible to compare the proportions of the categorical variables. To find an association between a dependent variable and perceived risk factors, the odds ratio (OR) with $95 \%$ confidence limits $(\mathrm{p}<0.05)$ were calculated.

For the assessment of nutritional status, the Weight for Age Z-score was calculated using the WHO ENA 2010 software. It was categorized as follows: normal Z-score between -1 and +1 , Underweight with a Z-score $<-1$ moderately underweight with a $Z$-score $<-2$, severe underweight with a $Z$-score $<-3$.

\subsection{Ethical Considerations}

The essential principles related to the non-nuisance and anonymity of the patients were respected. Prior to the study, a research permit was granted by the Faculty of Medicine. Similarly, we obtained the discharge from the administration of the hospitals where the data collection was carried out.

\section{Results}

We collected about 321 cases of bronchiolitis out of a total of 8,454 infants admitted to hospital over a two-year study period from January 2013 to December 2014 with a frequency of $3.80 \%$ (Figure 1).

Bronchiolitis occurred most from December (8.7\%) until March (8.7\%), and the peak was observed in February or 24.9\% of the cases. This corresponds to the great rainy season in our environment.

According to this table, children from 1 to 6 months are the most vulnerable ( $54.80 \%$ of the cases) followed by those of 7 to 12 months $(23.00 \%)$. With a median calculated at 5 months $(\mathrm{P} 25=2, \mathrm{P} 75=15)$. With an average calculated at $7.78 \pm 6.43$ months; Extremes 1 month and 24 months (Table 1).

The male sex is the most affected, that is $56 \%$ of the cases and the sex ratio was estimated at 1.26 in favor of the male sex.

The communes of Kampemba and Lubumbashi are the most affected by the pathology with $43.61 \%$ and $29.60 \%$ of cases, respectively.

The prevalence of underweight was $40.6 \%(\mathrm{n}=129)$, distributed as follows: $17 \%(\mathrm{n}=54)$ of moderate malnutrition and $23.6 \%(\mathrm{n}=75)$ of severe malnutrition (Table 2).

This table shows a significant association between the evolution of the pathology and the history of prematurity $(\mathrm{p}=0.00)$. A preterm infant is 111 times more likely to die from bronchiolitis. A significant association was then observed 


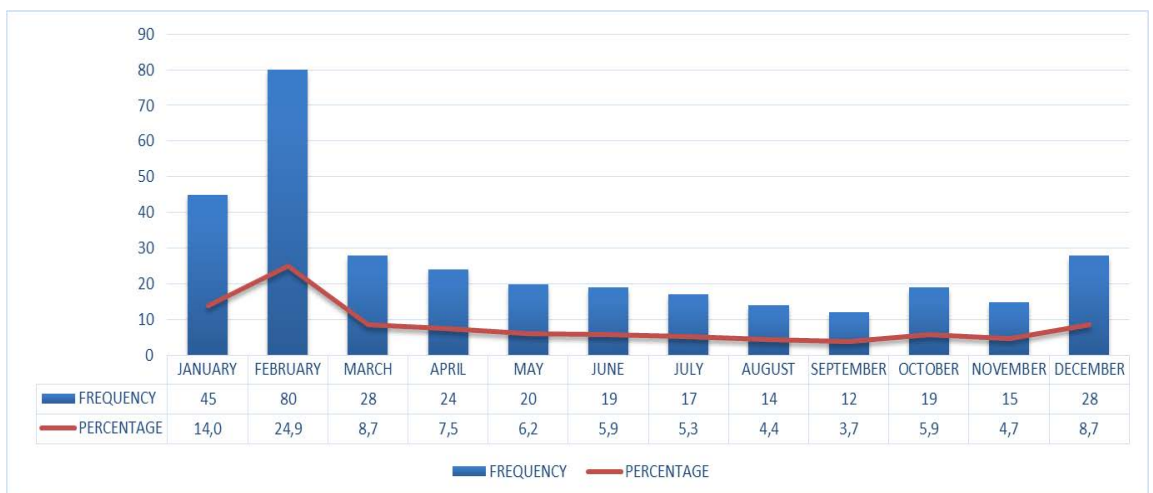

Figure 1. Distribution of cases by seasonality.

Table 1. Distribution of cases by socio-demographic parameters.

\begin{tabular}{|c|c|c|c|c|}
\hline Settings & Categories & Frequency & Percentage & Other parameters \\
\hline \multirow{4}{*}{ Age } & $1-6$ months & 176 & $54.80 \%$ & \\
\hline & 7 - 12 months & 74 & $23.00 \%$ & Median: 5 \\
\hline & $13-18$ months & 42 & $13.00 \%$ & $\mathrm{P} 25=2, \mathrm{P} 75=15$ \\
\hline & $19-24$ months & 29 & $9.10 \%$ & \\
\hline \multirow{3}{*}{ Sex } & Male & 180 & $56 \%$ & \\
\hline & & & & Sex ratio: 1.26 \\
\hline & Female & 141 & $44 \%$ & \\
\hline \multirow{8}{*}{ Residence Area } & Annex Area & 31 & $9.66 \%$ & \\
\hline & Kampemba & 140 & $43.61 \%$ & \\
\hline & Lubumbashi & 95 & $29.60 \%$ & \\
\hline & Katuba & 16 & $4.98 \%$ & \\
\hline & Kenya & 14 & $4.36 \%$ & \\
\hline & Ruashi & 14 & $4.36 \%$ & \\
\hline & Kipoushi & 1 & $0.31 \%$ & \\
\hline & Kamalondo & 10 & $3.12 \%$ & \\
\hline
\end{tabular}

Table 2. Distribution of cases according to the Weight for Age Z-score classification.

\begin{tabular}{ccc}
\hline Nutritional status (WfA Z-score) & Frequency & Percentage \\
\hline$\square-2 Z$-score $\geq$ WfA-3 & 54 & $17.0 \%$ \\
Z-score WfA $<-3$ & 75 & $23.6 \%$ \\
\hline
\end{tabular}

between the evolution of bronchiolitis and the presence of associated pathologies $(\mathrm{p}=0.02)$. Thus, with the presence of associated pathologies, an infant is 8 times more likely to die (Table 3 ).

An age of less than 6 months is significantly associated with a shorter duration 
Table 3. Distribution of cases according to the factors associated with the evolution of the pathology.

\begin{tabular}{|c|c|c|c|c|c|c|}
\hline & & \multicolumn{2}{|c|}{ Evolution } & \multirow{2}{*}{$\mathrm{p}$} & \multirow{2}{*}{ OR } & \multirow{2}{*}{ IC } \\
\hline & & Death & Healing & & & \\
\hline \multirow{2}{*}{$\begin{array}{l}\text { Antecedent of } \\
\text { Prematurity }\end{array}$} & Yes & 7 & 9 & 0.000 & 111 & 20.2 to 614.5 \\
\hline & No & 2 & 287 & & & \\
\hline \multirow{3}{*}{$\begin{array}{c}\text { Related } \\
\text { Pathologies }\end{array}$} & Yes & 8 & 194 & 0.02 & 8 & 0.9 to 64.5 \\
\hline & No & 1 & 194 & & & \\
\hline & & \multicolumn{2}{|c|}{ Duration of hospitalization } & & & \\
\hline \multirow{3}{*}{ Age } & & $<5$ days & $\geq 5$ jours & & & \\
\hline & $\leq 6$ mois & 150 & 50 & 0.00 & 0.2 & $0.1-0.4$ \\
\hline & $>6$ months & 97 & 24 & & & \\
\hline
\end{tabular}

of stay (less than 5 days) $(\mathrm{p}=0.00, \mathrm{OR}=0.2(0.1-0.4))$. The average length of stay is $6.04 \pm 6$ days.

\section{Discussion}

This study has some limitations. First, the diagnosis of bronchiolitis was mainly based on the assessment of the physician in charge of the patient, which implies that a rare number of cases considered as bronchiolitis could have been other pathologies associated with dyspnea and sibilance. Secondly, our retrospective and multicentric study suffered from the lack of homogeneity of patient records, which differed from one hospital to another, and the lack of certain socio-demographic data, often incomplete from medical records. However, despite these limitations, the objectives of our study were reasonably achieved.

We collected about 321 cases of bronchiolitis out of a total of 8454 infants: a frequency of $3.80 \%$. This frequency is lower than that found in 1989 by Wembonyama as an hospital incidence in Lubumbashi, which was then at $11.3 \%$ [12]. This frequency is also lower than that of Bobossi with 20.9\% [11], Tall with $21.7 \%$ [21], Adonis with $14.6 \%$ [22] or Sawadogo with 11.6\% [23].

This relatively low frequency is explained by the fact that we have focused on hospitalized cases, therefore potentially serious. Therefore, moderate to mild cases may have been treated on an outpatient basis and have not been collected in our series. Nevertheless, it is encouraging to note a possible improvement in hospital management in Lubumbashi when one considers the blatant difference in frequency in the above-mentioned study of 30 years ago. On the other hand, more improvement would probably be noted if public health measures, such as RSV vaccination, were initiated.

It was noted that children aged 1 to 6 months are the most vulnerable $(54.80 \%$ of the cases) followed by those of 7 to 12 months (23.00\%), i.e. a median calculated at 5 months (P25 =2, P75 = 15), the male sex is the most affected, that is to say $56 \%$ of the cases and the sex ratio was estimated at 1.26 in favor of the male 
sex. These figures are similar to most of the studies consulted, but there is no explanation for this fact [11] [12] [21] [22] [23].

For the period, bronchiolitis occurred most from December (8.7\%) until March (8.7\%), and the peak was observed in the month of February $24.9 \%$ of the cases that corresponds to the rainy season in our environment. Indeed, the moisture would be favorable to the spread of RSV, the main causative agent of the bronchiolitis of the infant.

Our study shows a strong association between the evolution of the pathology and the antecedent of prematurity $(\mathrm{p}=0.00)$. A preterm infant is 111 times more likely to die from bronchiolitis. There is also a significant association between the evolution of bronchiolitis and the presence of associated pathologies $(\mathrm{p}=$ 0.02 ). Thus, with the presence of associated pathologies, an infant is 8 times more likely to die.

The average length of stay is $6.04 \pm 6$ days. An age of less than 6 months was associated with a longer stay (more than 5 days). In one study, Bogne et al. Found an average hospital stay of 5 days. Complications were relatively lower in the series, except for cases of bacterial superinfection. Results close to ours [16].

In relation to nutritional status, the prevalence of underweight is $40.6 \%$. In Tshikaji in another DR Congo province, Musumbu et al. Have found that the histogram of Z-scores for age shows a curve deviated toward negative values, with a $Z$-weight-for-mean score of $-1.31 \pm 1.29$. And in its series, $40.2 \%$ of children had good nutritional status, compared with $28.3 \%$ who were malnourished. No children were overweight [12]. Meanwhile, According to the findings of a study of acute respiratory infections and nutritional status in children aged 0 - 5 years with in University Clinics of Lubumbashi, Democratic Republic of Congo [18], it appears that in fact nearly $70 \%$ of children have precarious nutritional status and nutritional status, they had $41.2 \%$ of cases of ARI with proven malnutrition. This highlights the probable role of poor nutritional status that may favor the occurrence or perpetuation of bronchiolitis in infants.

\section{Conclusion}

This study shows that bronchiolitis constitutes a real health issue for the child, given its frequency. This highlights the importance of integrating an RSV vaccine into the vaccine schedule. Taking action on known risk factors, including prematurity and a globally deleterious state of health by the coexistence of associated pathologies, would help to reduce this frequency.

\section{References}

[1] Wittig, H.J., Cranford, N.J. and Glaser, J. (1959) The Relationship between Bronchiolitis and Childhood Asthma. Journal of Allergy, 1, 19-23. https://doi.org/10.1016/0021-8707(59)90054-1

[2] Conference of Consensus (2000) Management of Bronchiolitis in Infants, LouisArmand Hall, Science and Industry City of La Villette, Paris, 21 September 2000.

[3] Bourillon, A., Grégoire, B. and Christopher, D. (2016) Pediatrics. 6th Edition, Ref- 
erence of the Colleges, Adapted to the National Classification Tests, 421.

[4] Wohl, S.E.M. (1994) Bronchiolitis in Children. In: Epler, G.R., Ed., Diseases of the Bronchioles, Raven Press, New York, 397-408.

[5] Broek, I., Harris, N., Henkens, M., Mekaoui, H., Palma, P.P., Szumilin, E. and Grouzard, V. (2010) Clinic and Therapeutic Guide for Curative Programs in Hospitals and Clinics. Doctors without Borders, Marsh, 64.

[6] Freymuth, F. (2007) Respiratory Syncytial Virus, Parainfluenza, Metapneumovirus and Human Virus: Clinical and Pathophysiology. The Pediatric Infectious Disease Journal, 285-290.

[7] Okoko, J.B., Wesumperuma, H.L. and Hart, C.A. (2001) The Influence of Prematurity and Low Birthweight on Transplacental Antibody Transfer in Rural West African Population. Tropical Medicine \& International Health, 6, 529-534.

[8] McIntosh, K. (1991) Pathogenesis of Severe Acute Respiratory Infections in Developing World: Respiratory Syncytial Virus and Parainfluenza Viruses. Reviews of Infectious Diseases, 13, 492-500. https://doi.org/10.1093/clinids/13.Supplement_6.S492

[9] Zouari, A., Smaoui, H., Brun, D., Njampeko, E., Sghaier, S., Zouari, E. and Kachrid, A. (2012) Prevalence of Bordetella pertussis Infections in Tunisian Hospitalized Infants: Results of 4-Year Prospective Study. Diagnostic Microbiology and Infections Disease, 72, 303-317.

[10] Cheron, G., Patteau, G. and Nouyrigat, V. (2009) Bronchiolitis in Infants. EMC (Elsevier BV), Emergency Medicine, 25-140-C-20.

[11] Bobossi, S.G., Bangue, C. and Mobima, T. (2004) Eidemiological, Clinical Ant Therapeutic of Acute Bronchiolitis in Infants in the Pediatric Complex of Bangui (Central African Republic). Medicine d'Afrique Noire, 2004, 217-222.

[12] Wembonyama, O.S. and Ngwanza, N.I. (1989) Acute Bronchiolitis in Infant: Epidemiological and Clinical Aspects in Zaire. Le Pédiatre, 25, 93-95.

[13] Musumbu, M.T., Mulowa, M.B., Mbuyi, J.P. and Beya, K.B. (2015) Study of Some Epidemiological, Clinical, Nutritional and Therapeutic Aspects of Bronchiolitis in Children Hospitalized in Bon Berger Hospital in Tshikaji, Kasai Occidental, RD Congo. Revue Medicale des grands Lacs/Great Lakes, 4, 41-45.

[14] Zorc, J.J. and Hall, C.B. (2010) Bronchiolitis: Recent Evidence on Diagnosis and Managment. Journal Pediatrics, 125, 342-349. https://doi.org/10.1542/peds.2009-2092

[15] American Academy of Pediatrics (AAP) Subcommittee on Diagnosis and Management of Bronchiolitis (2006) Diagnosis and Management of Bronchiolitis. Pediatrics, 118, 1774-1793. https://doi.org/10.1542/peds.2006-2223

[16] Bogne, J.B., Chiabi, A., Yatchet Tchatat, D., Nguefack, S., Mah, E., Tchokoteu, P.F and Mbonda, E. (2013) Acute Bronchiolitis in Infant Less than 24 Months in Yaoundé (About 296 Cases). Original Article, Yaoundé, 1.

[17] Salles, E. (2014) Management of Acute Bronchiolitis in Infant by General Practitioner in Hauts-De-Seine: Evaluation of Knowledge and Their Application. Bicêtre Hospital, Perpignan.

[18] Kabamba, N.L., Mbombo, D., Nduwa, K., Abasiko, M.A., Kaj, K.N., Ngolomba, J., Kakez, N.D. and Luboya, N.O. (2014) Acute Respiratory Infection and Nutritional Status in Children 0-5 Years: University Clinics of Lubumbashi, DR Congo. Pan African Medical Journal, 19, 393.

[19] Bakonde, B., Tatagan, K., Kessie, K., Kafechina, A.B.L., Assimadi, K., Paupe, J. and Scheinman, P. (1998) Hospital Epidemiology of Acute Lower Respiratory Infec- 
tionsr in Togolese Children. Médecine d'Afrique Noire, 45, 7.

[20] Guedehoussou, T. (1990) Acute Respiratory Infections in Children in Togo; Epidemiological, Clinical and Therapeutic Aspects: About a Prospective Study of 530 Cases Observed in Pediatrics Department of CHU-TOKOIN Lomé. Medical Thesis, Lomé.

[21] Tall, F.R., Valian, A., Curtis, V., Traore, A., Nacro, B., Cousens, S., et al. (1994) Acute Respiratory Infections in Pediatric Hospital of Bobo Dioulasso (Burkina Faso). Archives Francaises De Pediatrie, 1, 249-254.

[22] Adonis L.V., Tanoh, F.A., Ngoan, A.M., Camara, R., Kouadio, A.V., Amangoua, E., et al. (1994) General Profile of Lower Respiratory Diseases Children in CHU Yopougon. Publications médicales Africaines, 129, 29-34.

[23] Sawadogo, S.A., Sanou, I., Kam, K.L., Reinhardt, T.M., Koueta, F., Dao, L., et al. (1997) Acute Bronchiolitis of Infants in Pediatric Hospital in Burkina Faso. Annales de pédiatrie, 44, 493-499. Expansion Scientifique Publications

Submit or recommend next manuscript to OALib Journal and we will provide best service for you:

- Publication frequency: Monthly

- 9 subject areas of science, technology and medicine

- Fair and rigorous peer-review system

- Fast publication process

- Article promotion in various social networking sites (LinkedIn, Facebook, Twitter, etc.)

- Maximum dissemination of your research work

Submit Your Paper Online: Click Here to Submit

Or Contact service@oalib.com 